\title{
Protective Effects of Platelet-rich plasma for in vitro Fertilization of Rats with Ovarian Failure Induced by Cyclophosphamide
}

\section{Efeitos protetores do plasma rico em plaquetas para fertilização in vitro de ratos com falência ovariana induzida por ciclofosfamida}

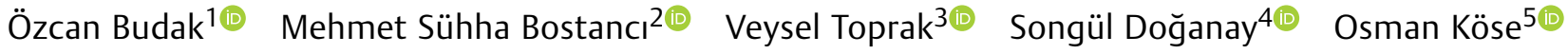

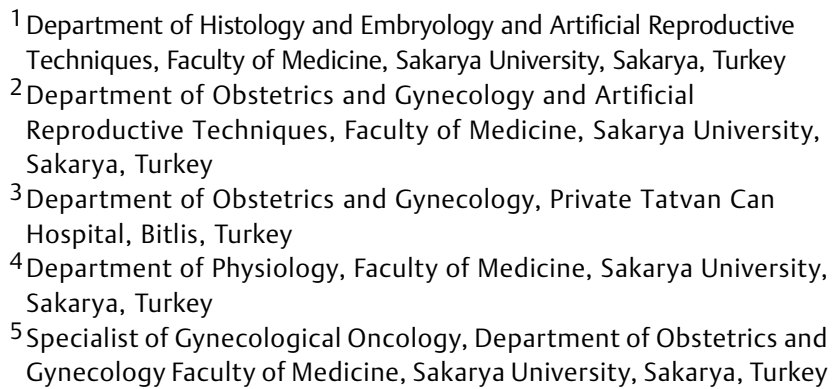

Address for correspondence Mehmet Sühha Bostancı, Department of Obstetrics and Gynecology and Artificial Reproductive Techniques, Faculty of Medicine, Sakarya University, Sakarya, Turkey (e-mail: msbostanci@sakarya.edu.tr).

Rev Bras Ginecol Obstet 2022;44(2):161-168.

\begin{abstract}
Keywords

- ovary

- premature ovarian insufficiency

- cyclophosphamide

- in vitro fertilization

- platelet-rich plasma

Objective Premature ovarian insufficiency (POI) contributes significantly to female infertility. Cyclophosphamide (CYC has adverse effects on folliculogenesis. Platelet-rich plasma (PRP) is an autologous product rich in many growth factors. We evaluated the protective effect of PRP on in vitro fertilization in female rats with CYC-induced ovarian damage.

Methods Twenty-eight adult female Sprague-Dawley rats were randomly divided into four groups. Group 1 (control-sodium chloride $0.9 \% ; 1 \mathrm{~mL} / \mathrm{kg}$, single-dose intraperitoneal [IP] injection); group 2 (CYC), $75 \mathrm{mg} / \mathrm{kg}$, single-dose IP injection and sodium chloride $0.9 \%$ ( $1 \mathrm{~mL} / \mathrm{kg}$, single-dose IP injection); group 3 CYC plus PRP, CYC (75 mg/kg, single-dose and PRP (200 $\mu$ l, single-dose) IP injection); and group 4 (PRP, $200 \mu$, singledose IP injection).

Results In the comparisons in terms of M1 and M2 oocytes, it was observed that the CYC group presented a significantly lower amount than the control, CYC/PRP, and PRP groups. (for $\mathrm{M} 1, p=0.000, p=0.029, p=0.025$; for $\mathrm{M} 2, p=0.009, p=0.004$, $p=0.000$, respectively). The number of fertilized oocytes and two-celled good quality embryos was found to be statistically significant between the CYC and control groups, CYC + PRP and PRP groups ( $p=0.009, p=0.001, p=0.000$ for oocytes, respectively. For embryos; $p=0.016, p=0.002, p=0.000)$.
\end{abstract}

received

January 14, 2021

accepted

October 5, 2021
DOI https://doi.org/ 10.1055/s-0041-1741451. ISSN 0100-7203. (c) 2022. Federação Brasileira de Ginecologia e Obstetrícia. All rights reserved.

This is an open access article published by Thieme under the terms of the Creative Commons Attribution License, permitting unrestricted use, distribution, and reproduction so long as the original work is properly cited. (https://creativecommons.org/licenses/by/4.0/)

Thieme Revinter Publicações Ltda., Rua do Matoso 170, Rio de Janeiro, RJ, CEP 20270-135, Brazil 


\section{Resumo}

\author{
Palavras-chave \\ - ovário \\ - insuficiência \\ ovariana prematura \\ - ciclofosfamida \\ - fertilização in vitro \\ - plasma rico em \\ plaquetas
}

Conclusion Platelet-rich plasma can protect the ovarian function against damage caused by CYC, and, in addition, it improves oocyte count and the development of embryos as a result of oocyte stimulation during the IVF procedure.

Objetivo A insuficiência ovariana prematura (POI) contribui significativamente para a infertilidade feminina. A ciclofosfamida (CYC) tem efeitos adversos na foliculogênese. O plasma rico em plaquetas (PRP) é um produto autólogo rico em muitos fatores de crescimento. Avaliamos o efeito protetor do PRP na fertilização in vitro em ratas com lesão ovariana induzida por CYC.

Métodos Vinte e oito ratas Sprague-Dawley adultas foram divididas aleatoriamente em quatro grupos. Grupo 1 (controle - cloreto de sódio $0,9 \% ; 1 \mathrm{~mL} / \mathrm{kg}$, injeção intraperitoneal [IP] em dose única); grupo 2 (CYC), $75 \mathrm{mg} / \mathrm{kg}$, injeção IP de dose única e cloreto de sódio $0,9 \%(1 \mathrm{~mL} / \mathrm{kg}$, injeção ip de dose única); grupo 3 CYC + PRP, CYC ( $75 \mathrm{mg} / \mathrm{kg}$, dose única e PRP (200 $\mu$ l, dose única) injeção IP); e grupo 4 (PRP, $200 \mu$, injeção IP de dose única).

Resultados Nas comparações em termos de ovócitos M1 e M2, observou-se que o grupo CYC apresentou uma quantidade significativamente menor que os grupos controle, CYC/PRP, e PRP. (Para M1, $p=0,000, p=0,029, p=0,025$; para M2, $p=0,009, p=0,004, p=0,000$, respectivamente). O número de oócitos fertilizados e embriões bicelulares de boa qualidade foi considerado estatisticamente significativo entre os grupos CYC e controle, CYC + PRP e grupos PRP $(p=0,009, p=0,001$, $p=0,000$ para oócitos, respectivamente. Para embriões, $p=0,016, p=0,002$, $p=0,000)$.

Conclusão O PRP pode proteger a função ovariana contra os danos causados pelo CYC e, além disso, proporciona melhora na contagem de oócitos e no desenvolvimento de embriões como resultado da estimulação ovariana durante o procedimento de fertilização in vitro.

\section{Introduction}

While ovarian reserve is defined as the number of follicles/oocytes present in the ovaries, premature ovarian insufficiency (POI) is defined as a decrease in ovarian functions and oocyte reserve before the age of $40 .^{1}$ The prevalence of POI is estimated to be around 1 to $3 \%$ among women when the general population is evaluated. ${ }^{2}$ Most POIs are classified as idiopathic. ${ }^{3}$ However, the pathophysiology of $\mathrm{POI}$ is thought to be related to genetic factors, radiotherapy, and chemotherapy factors, autoimmune disorders, and infections. ${ }^{3}$ Premature ovarian insufficiency results in premature loss of ovarian function, major health problems, and infertility, especially as a result of the decreased number of oocytes in the ovaries due to accelerated atresia. In case of sufficient residual ovarian reserve, in vitro fertilization (IVF) with autologous oocytes obtained by ovarian stimulation is an effective treatment for women with POI. ${ }^{4}$

Platelet-rich plasma (PRP) is an autologous product rich in many growth factors, such as platelet-derived growth factor (PDGF), transforming growth factor (TGF)- $\beta$, and vascular endothelial growth factor (VEGF). ${ }^{5,6}$ Growth factors in PRP stimulate chemotaxis, proliferation, and differentiation of stem cells and angiogenesis in a way that accelerates tissue repair. ${ }^{7,8}$ Platelet-rich plasma, which is an inexpensive product compared with many other agents, has many advantages, such as being easy to obtain and having an antimicrobial effect as well as being an autologous product. $^{9}$

Alkylating chemotherapy agents such as cyclophosphamide (CYC), which are highly gonad-toxic, cause a decrease in ovarian function and have detrimental effects on the female reproductive organs. ${ }^{10}$ These effects of CYC are primarily due to the inhibition of DNA synthesis and function and induction of DNA damage. Cyclophosphamide has been shown to reduce primitive follicles, oocytes, and granulosa cells on eggs by inducing apoptosis, inhibiting angiogenesis, thus causing ovarian atrophy. ${ }^{11}$

Pathological changes in CYC-generated POI patterns are similar to clinical observations in POI patients, and these pathological changes in the POI model can be reversed with drugs. ${ }^{12}$

Growth factors such as VEGF, EGF, PDGF, and TGF-have been shown to have protective effects on ovarian damage. $^{6,13-15}$ Platelet-rich plasma has been found to have a predominant positive effect on ovarian cortex volume, antral follicle number and antral follicle diameter on ovarian damage caused by CYC. ${ }^{12,16}$ 
There are various medical treatments, such as immunomodulating therapies, apoptotic inhibitors, antioxidant therapies, IVF, and embryo transfer using donor oocytes to restore impaired ovarian function and/or restore fertility in women with POI. ${ }^{17}$ Women with POI require significantly higher doses of exogenous gonadotropin to initiate folliculogenesis compared with patient groups with normal ovarian reserve. ${ }^{4}$ They commonly have a poor response to stimulation, with only four or fewer follicles available for oocyte retrieval. ${ }^{4}$ It seems that not every approach applied to remedy this situation can be created as effective or guaranteed for successful management. ${ }^{4}$ The protective and curative effect of PRP at the level of folliculogenesis in CYCinduced ovarian damage has been shown in previous studies. ${ }^{12,16}$ A recent study has shown that intraovarian injection of autologous PRP has improved IVF results in women with primary ovarian insufficiency. ${ }^{18}$ The aim of this study is to investigate the protective effect of PRP on in vitro fertilization in female rats with CYC-induced ovarian damage.

\section{Methods}

The study was conducted in Sakarya University's SÜDETAM laboratory under the authority of Sakarya University's experimental animal ethics committee on 04/11/2020 under decision No.62. Applications for all research animals were performed according to the "The European Commission Directive 86/609/ECC guideline" protocol. Twenty-eight adult female Sprague-Dawley rats (weight 200-250g; age 65-75 days) were provided by the Sakarya University Animal Reproduction Center and housed in groups with ad libitum food and water in the Animal Laboratory of Sakarya University. The holding room was maintained at room temperature of $22 \pm 2^{\circ} \mathrm{C}$ with humid conditions (45-55\%) and a 12-hour light/day cycle.

The rats were randomly divided into four different experimental (Exp.) groups:

Group I (control group) received sodium chloride $0.9 \%$ ( $1 \mathrm{~mL} / \mathrm{kg}$, single dose) intraperitoneal (IP) injection on the $1^{\text {st }}, 8^{\text {th }}$, and $15^{\text {th }}$ days.

Group II (CYC group) received cyclophosphamide (CYC) ( $75 \mathrm{mg} / \mathrm{kg}$, single dose) IP injection on the $1^{\text {st }}, 8^{\text {th }}$, and $15^{\text {th }}$, days.

Group III (CYC + PRP group) received CYC $(75 \mathrm{mg} / \mathrm{kg}$,

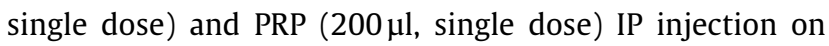
the $1^{\text {st }}, 8^{\text {th }}$, and $15^{\text {th }}$ days.

Group IV (PRP only group) received PRP ( $200 \mu$, single dose) IP injection on the $1^{\text {st }}, 8^{\text {th }}$, and $15^{\text {th }}$ days.

The stage of the estrous cycle of the rats was determined by performing daily vaginal smears after acclimation. Rats determined to have at least 3 consecutive 4-day estrous cycles were prepared for in vitro fertilization (IVF). All the rats were subjected to the IVF protocol to create hyperstimulation. On the day the stimulation was completed, female rats were sacrificed, and their oocytes were collected.

Human tubal fluid (HTF) medium (Cat. No. 90166, Irvine Scientific, Santa Ana, CA, USA) was used for sperm preincubation, fertilization, and embryo transfer. For sperm prein- cubation, a $200 \mathrm{~mL}$ droplet was used. For oocyte collection and IVF, a $100 \mathrm{~mL}$ volume droplet was used. Embryos were washed by passing through four such droplets. Each droplet was placed on a 35-mm culture dish (Nunc, Cat. No.63754, Denmark), covered with liquid paraffin oil (Cat. No. 9305, Irvine Scientific), and kept at $37^{\circ} \mathrm{C}$ under $5 \% \mathrm{CO} 2$ in humidified air overnight.

The ovaries were stimulated through the IP route for both ovaries in the female rats. For the first injection, we used an IP injection of 150 to 300 internal units (IUs)/kg of pregnant mare serum gonadotropin (PMSG) (Chronogest/PMSG, Intervet, Istanbul, Turkey), followed $\sim 48$ hour later by 150 to 300 IUs/kg of human chorionic gonadotropin (hCG; Gonatropin, Chorulon Intervet, Istanbul, Turkey). At 17 to 19 hours after hCG administration, 15 IUs of PMSG were administered. ${ }^{19}$ All the rats were weighed and anesthetized by an intramuscular administration of $50 \mathrm{mg} / \mathrm{kg}$ ketamine hydrochloric acid (Ketalar; Eczacibasi Warner-Lambert Ilac Sanayi, Levent, Istanbul, Turkey) and $7 \mathrm{mg} / \mathrm{kg}$ xylazine hydrochloric acid (Rompun, Bayer Sisli, Istanbul, Turkey). After immobilizing the rats on a standard surgery board, blood samples were collected to measure the level of serum anti-Mullerian hormone $(\mathrm{AMH})$. The aseptic technique was used to make a ventral midline incision to expose the reproductive organs, and the oviducts were removed. In this manner, the oocytes were collected from removed ovaries. To incubate the oocytes, HTF medium with the addition of $4 \mathrm{mg} / \mathrm{ml}$ of human serum albumin (HSA) was cultured for 1 day before being placed in an incubator at $37^{\circ} \mathrm{C}$ and $5 \% \mathrm{CO}_{2}$. Culture drops were prepared as group cultures on the culture dish under mineral oil. Fertilization, 2 washes, and culture drops were prepared in $500 \mu l, 150 \mu l$, and $150 \mu$ amounts, respectively. The oocytes and capacious sperm (approximate concentration $1 \times 106 \mathrm{ml}-1$ ) were transferred to the fertilization drops. Then, fertilization was checked, and the fertilized oocytes were washed and transferred to culture drops, and the resulting embryos were monitored up to the blastocyst stage. $^{20}$

Before the oocyte collection, a mixture of $75 \mathrm{mg} / \mathrm{kg}$ of ketamine (Ketasol, Richter Pharma, Austria) and $10 \mathrm{mg} / \mathrm{kg}$ of xylazine (Basilazin, Bavet, Turkey) was applied intraperitoneally to a male rat, and then the rat was euthanized. Following the euthanasia procedure, the male reproductive system was surgically opened from the abdomen, and the left and right epididymis were separated from the testicles and transferred to HTF medium containing $1 \mathrm{ml}$ of HTF (Cat. No. 90168 , Irvine Scientific, USA) and $4 \mathrm{mg} / \mathrm{ml}$ of bovine serum albumin (BSA). The epididymis was carefully peeled off using forceps, and the sperm were transferred into petri dishes and incubated at $37^{\circ} \mathrm{C}$ for 30 minutes before in vitro fertilization. $^{21}$

Approximately 6.5 hours after insemination, the oocytes were washed 3 times with HTF medium and cultured as above. At 7 to 8 hours after insemination, the oocytes were checked for sperm penetration or pronuclear formation under an inverted microscope to identify any polyspermic fertilization or parthenogenetic embryos $(\sim 6.5 \%$ of the total). After culturing for a further 20 hours, the numbers 
of 2-cell stage embryos were counted; these were defined as fertilized embryos.

Eight mature male Sprague-Dawley rats were used to prepare PRP. Blood samples were taken from these rats by heart puncture from the right ventricle under anesthesia and taken into test tubes containing 3.2\% sodium citrate (Merck, Darmstadt, Germany) at the rate of $9 / 1$ blood/citrate. After the blood samples were centrifuged at $400 \times$ for 10 minutes, the upper part of the plasma containing the platelets and buffy coat was transferred to another tube and centrifuged again at $800 \times \mathrm{g}$ for 10 minutes. This tube contained platelet deposits and some red blood cells (an erythrocyte-platelet cluster). By removing the upper $2 / 3$ of the supernatant containing platelet-poor plasma, the remaining layer (lower $1 / 3$ ) was accepted as PRP. The final fraction, containing $2.4 \times 106$ platelets/ml, was $\sim 3.9$ times larger than the blood platelet count $(570,000$ platelets/ $/ \mathrm{l})$. We used fresh PRP per administration.

Anti-Mullerian hormone was quantitatively estimated in rat serum samples using enzyme-linked immunosorbent assay (ELISA) kits (MyBioSource, Rat AMH ELISA Kit Catalog No: MBS2509909, San Diego, California, USA).

Statistical analyses were performed using the IBM SPSS Statistics for Windows, Version 24.0 software (IBM Corp., Armonk, NY, USA). The Shapiro-Wilk test was used to evaluate the normal distribution of the data. For the comparison of more than two variables, one-way analysis of variance (ANOVA) was used for normally distributed data and the Kruskal-Wallis test was used for data that did not show normal distribution. To determine which group was different from the others, the Tukey honestly significant difference (HSD) test was used for variables with homogeneous variances, and the Tamhane T2 test for non-homogeneous variables. The results are given as mean \pm standard error (SE). The statistical evaluation was considered significant when $p<0.05$ for each test.

\section{Results}

The oocytes were classified as germinal vesicle (GV), metaphase I (M1), and metaphase II (M2). To compare the meiotic progression during oocyte maturation in different systems, the average time that each stage of nuclear progression takes was calculated. This method was previously described by Sirard et al. ${ }^{22}$ As a result of the statistical evaluation made in the light of this situation, it was seen that only cyclophosphamide (CYC) application decreased the average number of M1 and M2, increased the number of GVs, and PRP application prevented this effect of CYC ( - Fig. 1). In the comparisons in terms of M1 and M2 numbers, it was observed that the CYC group presented a significantly lower number than the control, CYC/PRP, and PRP groups (for M1, respectively: $p=0.000, \quad p=0.029, \quad p=0.025$; for $\mathrm{M} 2$, respectively: $p=0.009, p=0.004, p=0.000$ ). In the evaluation made in terms of the GVs number, it was observed that the GVs number increased in the CYC group, and the PRP application decreased the GVs number. In the comparisons between groups, the GV value in the CYC group was significantly

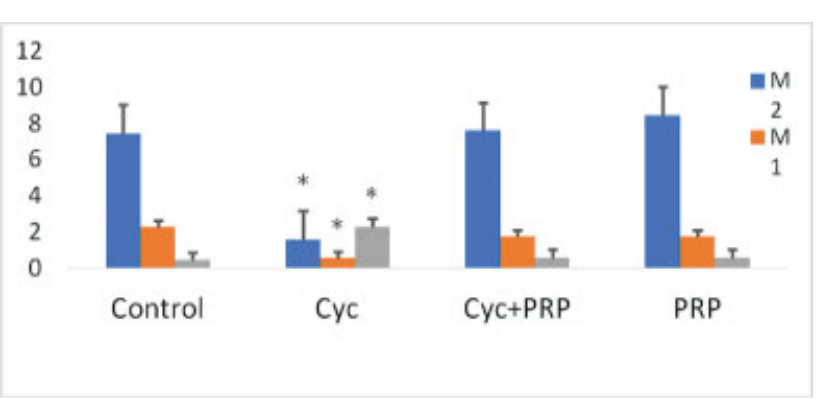

Fig. 1 Comparison of the mean of metaphase I (M1), metaphase II (M2) oocytes and germinal vesicles (GVs) in experimental groups. Abbreviations: Control, control group; CYC, cyclophosphamide administered group; CYC + PRP, cyclophosphamide and platelet rich plasma applied group; PRP, platelet-rich plasma applied group. * $p<0.05$ compared with the control, CYC + PRP, and PRP groups. Values are given as mean and standard error.

higher compared with the control, CYC + PRP, and PRP groups ( $p=0.001, p=0.003, p=0.003$, respectively). When the CYC + PRP group was compared with the control and PRP groups, there was no significant difference in terms of MI, MII, GV, and oocyte count ( $p>0.05$ ). The average number of oocytes, fertilized oocytes and two-celled good quality embryos belonging to the groups are presented in - Fig. 2 . The mean oocyte count was statistically significantly lower in the CYC group compared with the control, CYC + PRP, and PRP groups ( $p=0.000$ for each). When the CYC + PRP group and the control and PRP groups were compared in terms of mean oocyte count, there was no statistically significant difference between the groups $(p>0.05)$. The mean number of fertilized oocytes and two-celled good quality embryos was the lowest in the CYC group, while it was highest in the PRP only group. In the comparison between the groups, the number of fertilized oocytes and two-celled good quality embryos was found to be statistically significant between the CYC group and control, CYC + PRP, and PRP groups $(p=0.009, p=0.001$,

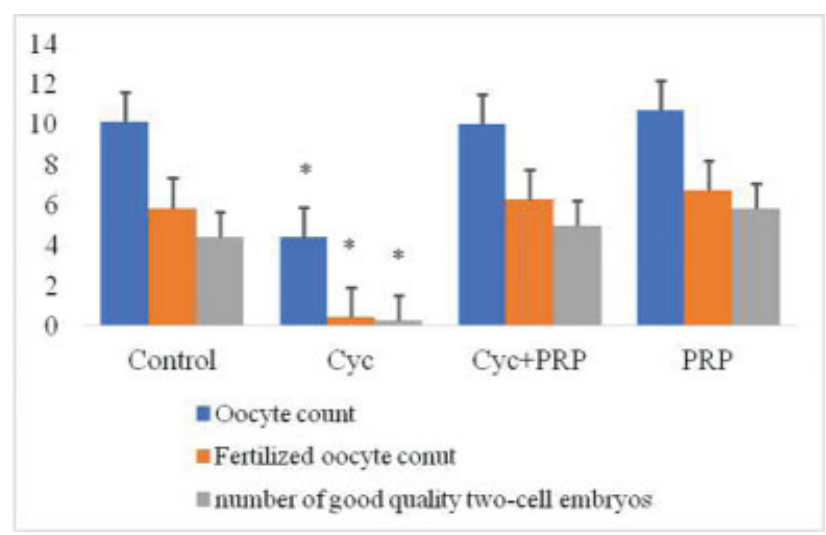

Fig. 2 Comparison of the mean numbers of total oocytes, fertilized oocytes, and two-celled good quality embryos in the experimental groups. Abbreviations: Control, control group; CYC, cyclophosphamide administered group; CYC + PRP, cyclophosphamide and PRP applied group; PRP, platelet-rich plasma applied group. ${ }^{*} p<0.05$ compared with control, CYC + PRP, and PRP group. Values are given as mean and standard error. 


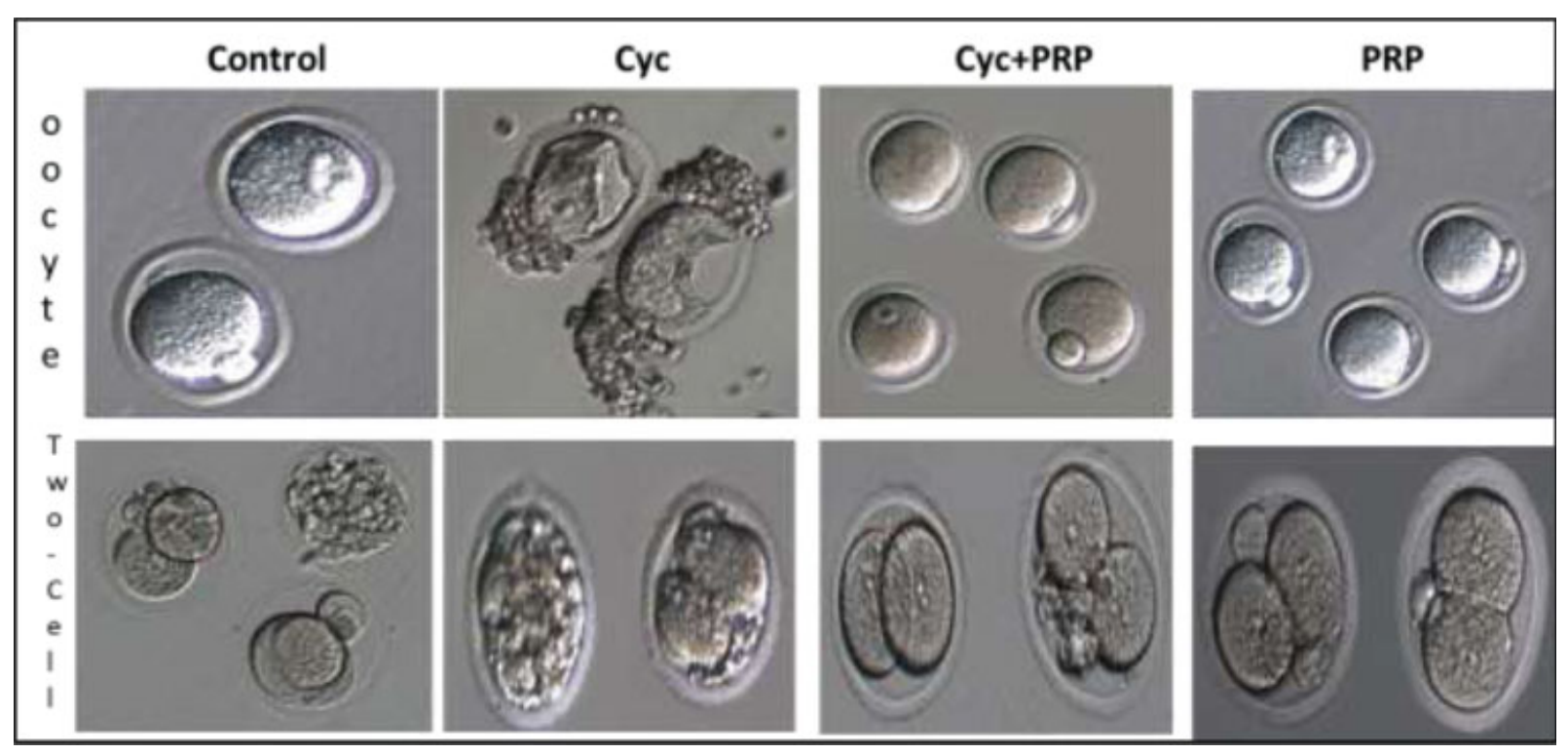

Fig. 3 Oocyte and two-cell embryo images of control, CYC, CYC + PRP and PRP groups, 200X magnification in inverted microscope. There are two M2 oocytes belonging to the control group, $3 \mathrm{M} 2$ and $1 \mathrm{GV}$ oocyte in the CYC + PRP group and $4 \mathrm{M} 2$ oocytes in the PRP group. In the CYC group, there are $2 \mathrm{GV}$ oocytes whose ooplasms are severely damaged. In the CYC group, the quality of the 2-cell embryo is very poor, with a high rate of fragmentation. While two-cell embryos with equal blastomeres are seen in the CYC + PRP and PRP groups, embryos with a very small amount of fragmentation are seen in the CYC + PRP group. Although embryos with equal blastomeres were seen in the CYC + PRP and PRP groups, embryos with a small amount of fragmentation were seen in the CYC + PRP group. Abbreviations: Control, control group; CYC, cyclophosphamide administered group; CYC + PRP, cyclophosphamide and platelet-rich plasma applied group; PRP, platelet-rich plasma applied group; GV, germinal vesicle; MII, metaphase II.

$p=0.000$ for fertilized oocytes, respectively. for the number of good quality embryos; $p=0.016, p=0.002, p=0.000$ ).

Two-celled embryos were obtained by culturing oocytes after IVF. In the CYC group, the quality of the two-celled embryo was very poor, a high rate of fragmentation was seen. Although embryos with equal blastomeres were seen in the CYC + PRP and PRP groups, embryos with a small amount of fragmentation were seen in the CYC + PRP group. This effect was thought to be due to CYC. In the control group, embryos with equal blastomeres were generally seen, however, it was seen in embryos with fragmentation (-Fig. 3).

When the AMH concentrations in the study groups were examined, it was found that it was the highest in the PRP group, while it was the lowest in the CYC group (-Fig. 4). It was observed that there was a statistically significant difference between the CYC and CYC + PRP groups when compared with the control group $(p=0.000)$.

\section{Discussion}

For ovarian failure, the presence of ovarian atrophy, follicle reduction, and sex hormonal diminution are used. ${ }^{23}$ Looking at society, ovarian failure (POI) is one of the most important diseases that cause infertility in women and threaten women's health. The early detection and treatment of ovarian dysfunctions continues to be an important research and clinical area of interest in gynecology. Infertile patients with aging ovaries - sometimes called the approaching POI, their numbers are increasing day by day and constitute a significant proportion of patients applying for IVF/ART. Current approaches to effective management of patients diagnosed with POI offer a wide range of options. Although egg donation (ED) is still the most successful and final treatment for POI patients, the vast majority of these infertile women are reluctant to consent to ED upon initial diagnostic interview and demand alternative solutions using their own autologous eggs, despite the low chance of success. ${ }^{24}$ Many researchers have investigated the use of stem cell transplantation, including human menstrual blood stem cells, fatderived stem cells, human endometrial mesenchymal stem cells, Platelet-rich plasma (PRP), as a cell therapy to reverse ovarian damage caused by chemotherapy. ${ }^{12,16,25,26}$ PRP has

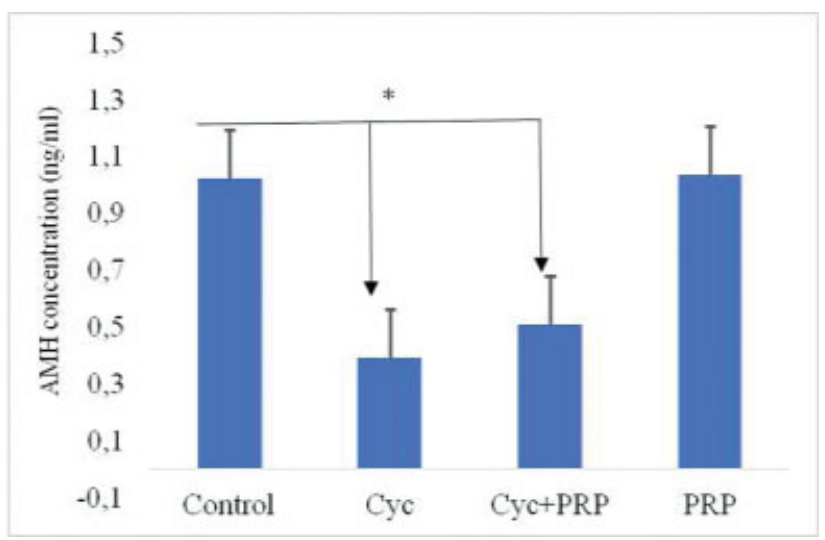

Fig. 4 Comparison of experimental groups serum anti-Mullerian hormone (AMH) concentrations. Abbreviations: Control, control group; CYC, cyclophosphamide administered group; CYC + PRP, cyclophosphamide and PRP applied group; PRP, platelet-rich plasma applied group. $p<0.05$, compared with the control group. Values are given as mean and standard error. 
been defined as a blood plasma fraction with a platelet concentration 4 to 5 times higher than the normal level, and its beneficial effect on tissue regeneration, angiogenesis activation, inflammation control and anabolism has already been demonstrated in many medical fields. ${ }^{27}$ The main components of PRP that contribute to tissue healing and regeneration, anabolism increase, differentiation and proliferation, angiogenesis activation, inflammation control can be listed as hormones, macrophages, neutrophils, cytokines and various growth factors. ${ }^{28,29}$ Therefore, the use of PRP is considered a justified and potentially successful opportunity to increase the fertility outcome in POI patients where the main problem is ovarian failure.

A POI model induced by cyclophosphamide (CYC) was used in the present study. Cyc is an alkylating agent which induce ovarian failure in animal models. ${ }^{30}$ It has been shown in previous studies that CYC disrupts the ultrastructure of granulosa cells and induces apoptosis and autophagy and eventually causes ovarian failure. ${ }^{30,31}$ Cyc has been shown to reduce ovarian weight and volume, reduce the number of different follicles and sex hormone levels, and increase atretic follicles. $^{12}$ In their study of agents that prevent chemotherapy-induced ovarian damage, Roness et al. ${ }^{32}$ noted that AS-101, AMH, imatinib, sphingosine-1-phosphate, granulocyte colony stimulating factor, bortezomib, and multi-drug resistance gene- 1 were effective in preventing chemotherapy-induced ovarian damage. ${ }^{32}$ Different mechanisms of action associated with different protective agents have been shown to be effective, including inhibition of follicle activation, anti-apoptosis effects, vascular effects, and gene upregulation. ${ }^{32}$ When this protective effect is evaluated in terms of PRP, there are studies showing the success of PRP. ${ }^{12,16}$ These studies were generally performed on ovarian tissue and were performed on oocytes obtained at the stage of folliculogenesis.

Growth factors play an important role in improving the structure and function of the ovaries, and different growth factors such as VEGF, EGF, PDGF, and TGF-b have been shown to have protective effects on ovarian damage. ${ }^{13,14,33}$ Plateletrich plasma has a protective effect against ovarian damage caused by CYC, as it has high amounts of these factors in its structure. This efficiency has been demonstrated in previous studies. ${ }^{12,16}$ This protective feature of PRP in POI patients is to protect follicle development and oocyte number during folliculogenesis. Except for the protective effects of PRP on the ovary, there are many studies on the effects of PRP on the endometrium. ${ }^{34}$ It has been shown that intrauterine PRP treatment supports endometrial growth and improves assisted reproductive outcome in patients with thin endometrium. ${ }^{35}$ In humans, PRP used in autologous ovarian transplantation to improve the vascularization and quality of the implant has been shown to increase transplant success resulting in live birth. ${ }^{36}$ There is no study on the effectiveness of PRP for POI patients who have serious difficulties in IVF applications. Human studies on the subject in the literature are only at the level of case reports. ${ }^{37,38}$

As a result of our study, it is seen that the addition of PRP treatment in the group where POI was created with CYC positively affected the results of subsequent IVF. This positive effect is valid for both the number of oocytes obtained by ovulation stimulation and the number of embryos on day 2 obtained after fertilization. When the day-2 embryos obtained were evaluated in terms of their quality, it was noted that there is a significant difference in the PRP applied group compared with the untreated group. This may be due to the fact that the PRP treatment could probably enrich the dysfunctional ovarian tissues with essential factors for neoangiogenesis, leading to tissue regeneration and reactivation. Although the effect of PRP on regenerative and repair processes in somatic tissues remains largely uncertain, growth factors contained in PRP content may have many critical roles in the ovaries through physiologically local effects such as cell growth, proliferation, differentiation, chemotaxis, angiogenesis, and formation. These growth factors control the release of the extracellular matrix and even other growth factors in close proximity to the release sites. ${ }^{39}$ Platelet-rich plasma can accelerate this process while supporting the self-repair of ovaries, follicles after chemotherapy, which already have the potential to repair itself. ${ }^{40}$

When the control group and the PRP-only group were compared, the number of oocytes obtained in the group receiving PRP and the number of embryos on day 2 were higher, but this result was not found to be statistically significant. This situation makes us think that PRP does not have a significant effect in conditions with normal ovarian function and reserve. It seems, the beneficial effect of PRP is only applied on damaged ovaries, and it has no effect on the normal structure for IVF cycles.

Anti-Mullerian hormone, a powerful marker of ovarian reserve, is a member of the transforming growth factor superfamily produced by the granulosa cells of the antral follicles in the ovary. ${ }^{41}$ Considering the AMH levels, there was an increase in the PRP-CYC group compared with the CYC group. However, the AMH levels following PRP treatment corresponded to the expected lower AMH levels in a POI case, although an improvement in overall reproductive potential was observed. Although the PRP-CYC group had a low AMH level that could be diagnosed with POI compared with the control group, this decrease is not as extreme as in the group without PRP treatment, and it is not at a low level that will allow more oocytes and embryos to be obtained as a result of IVF. This suggested that PRP could improve ovarian reserve by protecting ovarian granulosa cells. This evidence demonstrated the protective effects of PRP from CYC damage to the ovarian follicles.

\section{Conclusion}

The present study evaluated the number and quality of oocytes obtained after ovarian stimulation and the number and quality of embryos obtained on the second day after fertilization. Our study showed that PRP can protect the ovarian function against damage induced by CYC, but it provides an improvement in the number of oocytes and developing embryos as a result of the oocyte stimulation performed during the subsequent IVF procedure. However, 
investigating the implantation results of these embryos, and evaluating the ongoing pregnancy results will be a good target for future studies.

\section{Contributions}

All authors contributed to the design of the study and were involved in the data collection, data analysis and/or interpretation. All authors also contributed to manuscript writing/substantive editing and review and approved the final draft of the manuscript.

\section{Conflict of Interests}

The authors have no conflict of interests to declare.

\section{References}

1 De Vos M, Devroey P, Fauser BC. Primary ovarian insufficiency. Lancet. 2010;376(9744):911-921. Doi: 10.1016/S0140-6736(10) 60355-8

2 Shelling AN. Premature ovarian failure. Reproduction. 2010;140 (05):633-641. Doi: 10.1530/REP-09-0567

3 European Society for Human Reproduction and Embryology (ESHRE) Guideline Group on POI, Webber L, Davies M, Anderson R, Bartlett J, Braat D, et al; European Society for Human Reproduction and Embryology (ESHRE) Guideline Group on POI. ESHRE Guideline: management of women with premature ovarian insufficiency. Hum Reprod. 2016;31(05):926-937. Doi: 10.1093/humrep/dew027

4 Chae-Kim JJ, Gavrilova-Jordan L. Premature ovarian insufficiency: procreative management and preventive strategies. Biomedicines. 2018;7(01):2. Doi: 10.3390/biomedicines7010002

5 Christgau M, Moder D, Hiller KA, Dada A, Schmitz G, Schmalz G. Growth factors and cytokines in autologous platelet concentrate and their correlation to periodontal regeneration outcomes. J Clin Periodontol. 2006;33(11):837-845. Doi: 10.1111/j.1600051X.2006.00991.X

6 Lubkowska A, Dolegowska B, Banfi G. Growth factor content in PRP and their applicability in medicine. J Biol Regul Homeost Agents. 2012;26(02, Suppl 1):3S-22S

7 Bakacak M, Bostanci MS, İnanc F, Yaylali A, Serin S, Attar R, et al. Protective effect of platelet rich plasma on experimental ischemia/reperfusion injury in rat ovary. Gynecol Obstet Invest. 2016;81(03):225-231. Doi: 10.1159/000440617

8 Pintat J, Silvestre A, Magalon G, Gadeau AP, Pesquer L, Perozziello $A$, et al. Intra-articular injection of mesenchymal stem cells and platelet-rich plasma to treat patellofemoral osteoarthritis: preliminary results of a long-term pilot study. J Vasc Interv Radiol. 2017;28(12):1708-1713. Doi: 10.1016/j.jvir.2017.08.004

9 Cieslik-Bielecka A, Bielecki T, Gazdzik TS, Arendt J, Król W, Szczepanski T. Autologous platelets and leukocytes can improve healing of infected high-energy soft tissue injury. Transfus Apheresis Sci. 2009;41(01):9-12. Doi: 10.1016/j.transci.2009.05.006

10 Meirow D, Assad G, Dor J, Rabinovici J. The GnRH antagonist cetrorelix reduces cyclophosphamide-induced ovarian follicular destruction in mice. Hum Reprod. 2004;19(06):1294-1299. Doi: 10.1093/humrep/deh257

11 Soleimani R, Heytens E, Darzynkiewicz Z, Oktay K. Mechanisms of chemotherapy-induced human ovarian aging: double strand DNA breaks and microvascular compromise. Aging (Albany NY). 2011; 3(08):782-793. Doi: 10.18632/aging.100363

12 Dehghani F, Aboutalebi H, Esmaeilpour T, Panjehshahin MR, Bordbar H. Effect of platelet-rich plasma (PRP) on ovarian structures in cyclophosphamide-induced ovarian failure in female rats: a stereological study. Toxicol Mech Methods. 2018;28(09): 653-659. Doi: 10.1080/15376516.2018.1491662
13 Mendes FA, Coelho Aguiar JM, Kahn SA, Reis AH, Dubois LG, Romão LF, et al. Connective-Tissue Growth Factor (CTGF/CCN2) induces astrogenesis and fibronectin expression of embryonic neural cells in vitro. PLoS One. 2015;10(08):e0133689. Doi: 10.1371/journal.pone.0133689

14 Nagashima T, Kim J, Li Q Lydon JP, DeMayo FJ, Lyons KM, et al. Connective tissue growth factor is required for normal follicle development and ovulation. Mol Endocrinol. 2011;25(10): 1740-1759. Doi: 10.1210/me.2011-1045

15 McNatty KP, Juengel JL, Reader KL, Lun S, Myllymaa S, Lawrence $\mathrm{SB}$, et al. Bone morphogenetic protein 15 and growth differentiation factor 9 co-operate to regulate granulosa cell function. Reproduction. 2005;129(04):473-480. Doi: 10.1530/rep.1.0511

16 Ozcan P, Takmaz T, Tok OE, Islek S, Yigit EN, Ficicioglu C. The protective effect of platelet-rich plasma administrated on ovarian function in female rats with Cy-induced ovarian damage. J Assist Reprod Genet. 2020;37(04):865-873. Doi: 10.1007/s10815-02001689-7

17 van Kasteren Y. Treatment concepts for premature ovarian failure. J Soc Gynecol Investig. 2001;8(1, Suppl Proceedings)S58-S59

18 Cakiroglu Y, Saltik A, Yuceturk A, Karaosmanoglu O, Kopuk SY, Scott RT, et al. Effects of intraovarian injection of autologous platelet rich plasma on ovarian reserve and IVF outcome parameters in women with primary ovarian insufficiency. Aging (Albany NY). 2020;12(11):10211-10222. Doi: 10.18632/aging.103403

19 Hino C, Ueda J, Funakoshi H, Matsumoto S. Defined oocyte collection time is critical for reproducible in vitro fertilization in rats of different strains. Theriogenology. 2020;144:146-151. Doi: 10.1016/j.theriogenology.2020.01.006

20 Agca Y, Critser JK. Chapter 7 - Assisted reproductive technologies and genetic modifications in rats. In: Suckow MA, Weisbroth SH, Franklin CL, eds. The laboratory rat. 2nd ed Burlington: Academic Press; 2006:165-189

21 Seed J, Chapin RE, Clegg ED, Dostal LA, Foote RH, Hurtt ME, et al; ILSI Risk Science Institute Expert Working Group on Sperm Evaluation. Methods for assessing sperm motility, morphology, and counts in the rat, rabbit, and dog: a consensus report. Reprod Toxicol. 1996;10(03):237-244. Doi: 10.1016/0890-6238(96) 00028-7

22 Sirard MA, Florman HM, Leibfried-Rutledge ML, Barnes FL, Sims ML, First NL. Timing of nuclear progression and protein synthesis necessary for meiotic maturation of bovine oocytes. Biol Reprod. 1989;40(06):1257-1263. Doi: 10.1095/biolreprod40.6.1257

23 Ebrahimi M, Akbari Asbagh F. Pathogenesis and causes of premature ovarian failure: an update. Int J Fertil Steril. 2011;5(02): 54-65

24 Blumenfeld Z. Premature ovarian failure: etiology and possible prevention. Expert Rev Endocrinol Metab. 2009;4(02):173-181. Doi: 10.1586/17446651.4.2.173

25 Liu T, Huang Y, Zhang J, Qin W, Chi H, Chen J, et al. Transplantation of human menstrual blood stem cells to treat premature ovarian failure in mouse model. Stem Cells Dev. 2014;23(13):1548-1557. Doi: $10.1089 /$ scd.2013.0371

26 Sun M, Wang S, Li Y, Yu L, Gu F, Wang C, et al. Adipose-derived stem cells improved mouse ovary function after chemotherapyinduced ovary failure. Stem Cell Res Ther. 2013;4(04):80. Doi: $10.1186 /$ scrt231

27 Schmitz JP, Hollinger JO. The biology of platelet-rich plasma. J Oral Maxillofac Surg. 2001;59(09):1119-1121. Doi: 10.1053/ joms.2001.26801

28 Borrione P, Gianfrancesco AD, Pereira MT, Pigozzi F. Platelet-rich plasma in muscle healing. Am J Phys Med Rehabil. 2010;89(10): 854-861. Doi: 10.1097/PHM.0b013e3181f1c1c7

29 Foster TE, Puskas BL, Mandelbaum BR, Gerhardt MB, Rodeo SA. Platelet-rich plasma: from basic science to clinical applications. Am J Sports Med. 2009;37(11):2259-2272. Doi: 10.1177/ 0363546509349921 
30 Comish PB, Drumond AL, Kinnell HL, Anderson RA, Matin A, Meistrich ML, et al. Fetal cyclophosphamide exposure induces testicular cancer and reduced spermatogenesis and ovarian follicle numbers in mice. PLoS One. 2014;9(04):e93311. Doi: 10.1371/ journal.pone.0093311

31 Liu HZ, Tao YX, Luo P, Deng CM, Gu YP, Yang L, et al. Preventive effects of a novel polysaccharide from sepia esculenta ink on ovarian failure and its action mechanisms in cyclophosphamidetreated mice. J Agric Food Chem. 2016;64(28):5759-5766. Doi: 10.1021/acs.jafc.6b01854

32 Roness H, Kashi O, Meirow D. Prevention of chemotherapyinduced ovarian damage. Fertil Steril. 2016;105(01):20-29. Doi: 10.1016/j.fertnstert.2015.11.043

33 Uhm SJ, Gupta MK, Yang JH, Chung HJ, Min TS, Lee HT. Epidermal growth factor can be used in lieu of follicle-stimulating hormone for nuclear maturation of porcine oocytes in vitro. Theriogenology. 2010;73(08):1024-1036. Doi: 10.1016/j.theriogenology. 2009.11.029

34 Maleki-Hajiagha A, Razavi M, Rouholamin S, Rezaeinejad M, Maroufizadeh S, Sepidarkish M. Intrauterine infusion of autologous platelet-rich plasma in women undergoing assisted reproduction: A systematic review and meta-analysis. J Reprod Immunol. 2020;137:103078. Doi: 10.1016/j.jri.2019.103078

35 Molina A, Sánchez J, Sánchez W, Vielma V. Platelet-rich plasma as an adjuvant in the endometrial preparation of patients with refractory endometrium. JBRA Assist Reprod. 2018;22(01): 42-48. Doi: 10.5935/1518-0557.20180009
36 Callejo J, Salvador C, González-Nuñez S, Almeida L, Rodriguez L, Marqués L, et al. Live birth in a woman without ovaries after autograft of frozen-thawed ovarian tissue combined with growth factors. J Ovarian Res. 2013;6(01):33. Doi: 10.1186/17572215-6-33

37 Sfakianoudis K, Simopoulou M, Nitsos N, Rapani A, Pantou A, Vaxevanoglou $\mathrm{T}$, et al. A case series on platelet-rich plasma revolutionary management of poor responder patients. Gynecol Obstet Invest. 2019;84(01):99-106. Doi: 10.1159/000491697

38 Stojkovska S, Dimitrov G, Stamenkovska N, Hadzi-Lega M, Petanovski Z. Live birth rates in poor responders' group after previous treatment with autologous platelet-rich plasma and low dose ovarian stimulation compared with poor responders used only low dose ovarian stimulation before in vitro fertilization. Open Access Maced J Med Sci. 2019;7(19):3184-3188. Doi: 10.3889/ oamjms.2019.825

39 Fabi S, Sundaram H. The potential of topical and injectable growth factors and cytokines for skin rejuvenation. Facial Plast Surg. 2014;30(02):157-171. Doi: 10.1055/s-0034-1372423

40 Herraiz S, Buigues A, Díaz-García C, Romeu M, Martínez S, GómezSeguí I, et al. Fertility rescue and ovarian follicle growth promotion by bone marrow stem cell infusion. Fertil Steril. 2018;109 (05):908-918.e2. Doi: 10.1016/j.fertnstert.2018.01.004

41 Durlinger AL, Gruijters MJ, Kramer P, Karels B, Kumar TR, Matzuk MM, et al. Anti-Müllerian hormone attenuates the effects of FSH on follicle development in the mouse ovary. Endocrinology. 2001; 142(11):4891-4899. Doi: 10.1210/endo.142.11.8486 